\title{
Maternal and Neonatal Outcomes in Expectant Management of Early-Onset Severe Preeclampsia
}

\author{
Zohreh Tabasi $^{1}{ }^{\text {iD }}$, Elahe Mesdaghinia ${ }^{1}$, Masoumeh Abedzadeh-Kalahroudi ${ }^{2 *}$ (iD), \\ Hossein Akbari ${ }^{3}$, Mahsa Bandagi-Motlagh ${ }^{4}$ \\ ${ }^{I}$ Associate Professor, Department of Obstetrics and Gynecology, School of Medicine, Kashan University of Medical Sciences, \\ Kashan, Iran \\ ${ }^{2}$ Associate Professor, Trauma Nursing Research Center, Kashan University of Medical Sciences, Kashan, Iran \\ ${ }_{3}^{3}$ Associate Professor, Department of Statistics and Epidemiology, Faculty of Health, Kashan University of Medical Sciences, \\ Kashan, Iran \\ ${ }^{4}$ General Practitioner, Kashan University of Medical Sciences, Kashan, Iran \\ * Corresponding Author: Masoumeh Abedzadeh-Kalahroudi, Trauma Nursing Research Center, Kashan University of \\ Medical Sciences, Kashan, Iran. Email: abedzadeh@kaums.ac.ir
}

Received: 15.12 .2020

Accepted: 13.04 .2021

How to Cite this Article: Tabasi Z, Mesdaghinia E, Abedzadeh-Kalahroudi M, Akbari H, Bandagi-Motlagh M. Maternal and Neonatal Outcomes in Expectant Management of Early-Onset Severe Preeclampsia. Avicenna J Clin Med. 2021; 28(1): 28-35. DOI: $10.52547 /$ ajcm.28.1.28

\section{Abstract}

Background and Objective: Preeclampsia is one of the most critical complications of pregnancy observed in $2 \%-8 \%$ of all pregnancies. Severe preeclampsia has many maternal and neonatal complications that are more prevalent in early-onset preeclampsia. The present study aimed to determine the prevalence of maternal and neonatal outcomes of expectant management of severe preeclampsia before 34 weeks of gestation.

Materials and Methods: In this retrospective descriptive study, the medical records of 55 mothers who had severe preeclampsia before 34 weeks of gestation and underwent expectant management and those of their neonates within 2014-2019 in Kashan, Iran, were reviewed. The information extracted from the medical records included maternal and neonatal demographic variables and outcomes. All data were analyzed in SPSS software (version 16) using descriptive and inferential statistics. The p-values of less than 0.05 were considered significant.

Results: In this study, the rates of seizure, post-partum hemorrhage, intensive care unit admission, and platelet decline were 5.5\%, 1.8\%, 3.6\%, and $7.3 \%$, respectively. Moreover, $10.9 \%$ of mothers had renal failure, and therefore, elevated liver enzymes and hemolysis. Among the neonates, $44.7 \%$ and $12.7 \%$ of the cases had respiratory distress syndrome (RDS) and low Apgar scores, respectively. It was also revealed that $6.4 \%$ of the neonates had convulsions and pneumothorax (PTX), and neonatal mortality was observed in $6.4 \%$ of them. No significant relationship was observed between maternal outcomes and gestational age and between neonatal outcomes and the number of deliveries $(\mathrm{P}>0.05)$. However, renal failure outcomes had a significant relationship with the number of deliveries $(\mathrm{P}=0.023)$, meaning that all mothers with renal failure were nulliparous. It was found that gestational age had a significant relationship with the outcomes of neonatal death, low 5-minute Apgar score, low birth weight, RDS, and PTX ( $\mathrm{P}<0.05)$; in other words, lower gestational age led to higher mentioned neonatal outcomes.

Conclusion: Expectant management of early-onset preeclampsia was beneficial for neonates, and the implementation of regular and close monitoring in equipped centers would prevent the increase of maternal complications.

Keywords: Expectant Management, Preeclampsia, Pregnancy Outcome 


\title{
بررسى بيامدهاى مادرى و نوزادى درمان انتظارى در ير هاكلاميسى شديد و زودرس
}

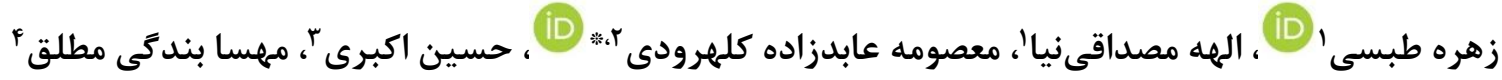

' انشيار، كروه زنان و زايمان، دانشكده يزشكى، دانشعاه علوم يزشكى كاشان، كاشان، ايران

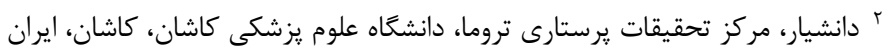

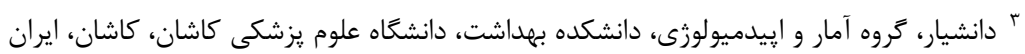

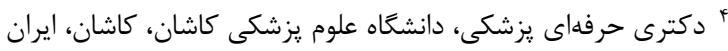

* نويسنده مسئول: معصومه عابدزاده كلهرودى، مركز تحقيقات يُرستارى تروما، دانشعاه علوم يزشكى كاشان، كاشان، ايران.

ايميل: abedzadeh@kaums.ac.ir

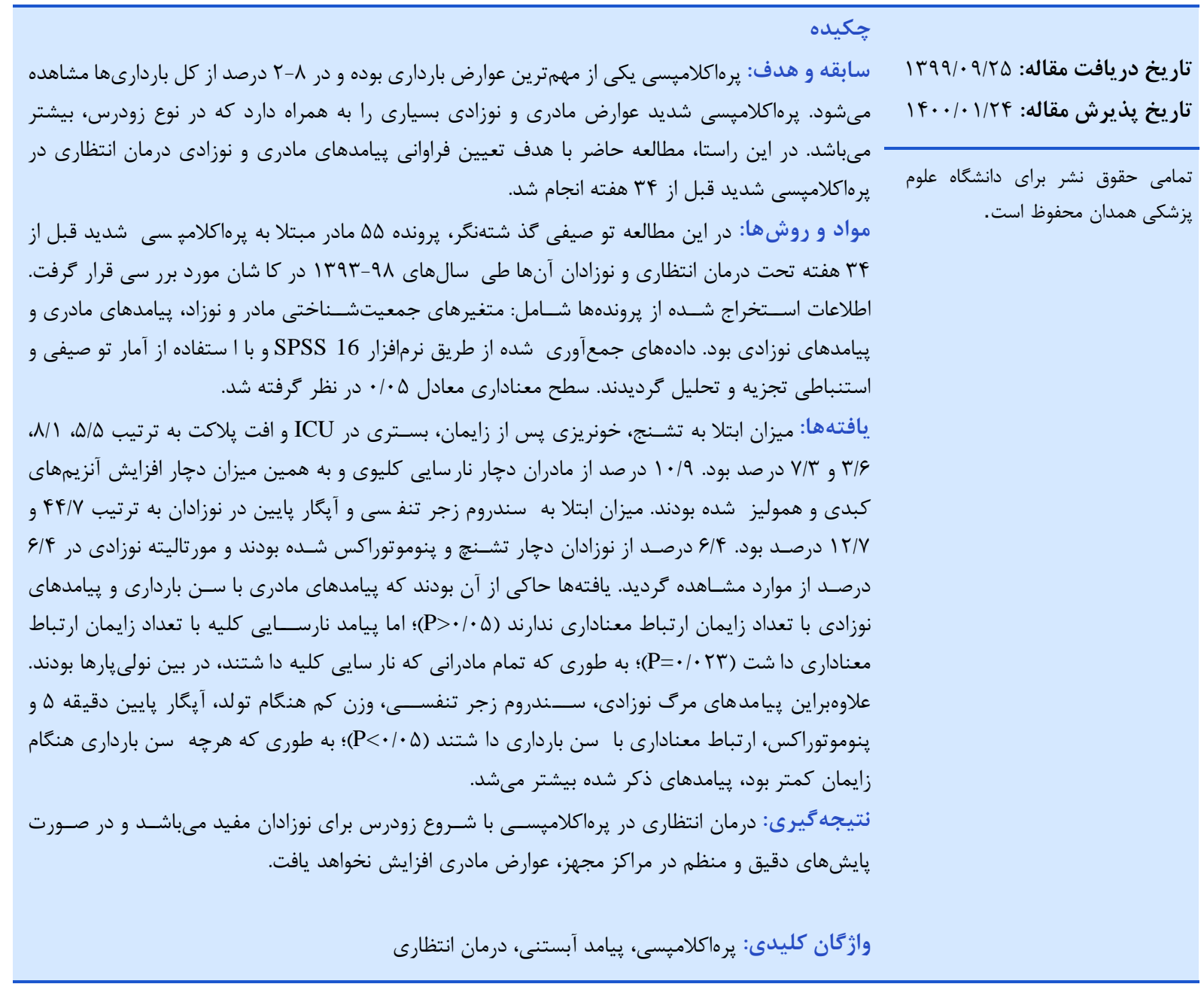

مقدمه

درصد گزارش شده و در سالهاى اخير رو به افزايش بوده است

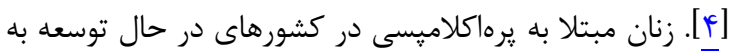

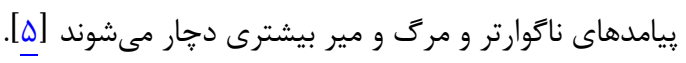

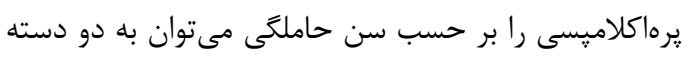

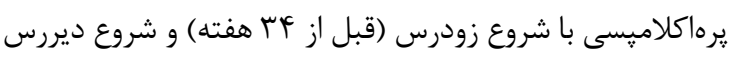

اختلالات هاييرتانسيو يكى از دلايل اصلى موربيديتى و

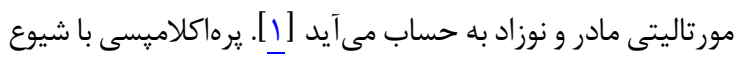

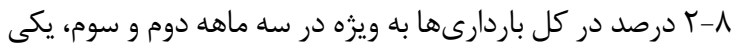

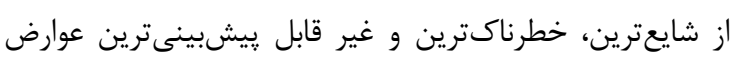

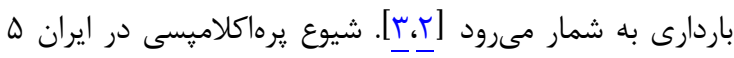




\section{مواد و روشها}

در اين مطالعه توصيفى كذشتهنكر، يرونده تمام زنان باردار

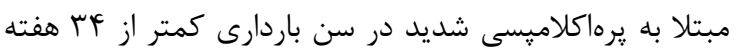

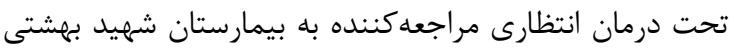

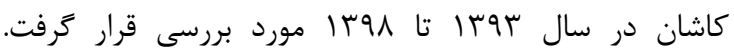

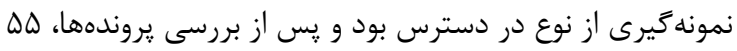

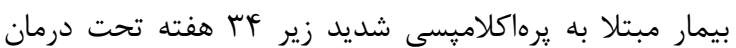

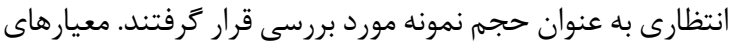

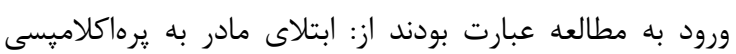

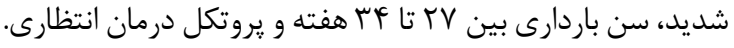

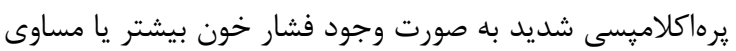

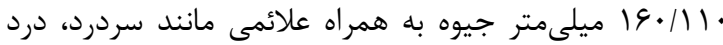

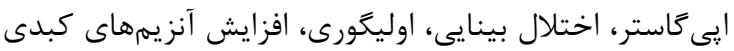

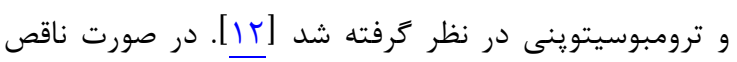

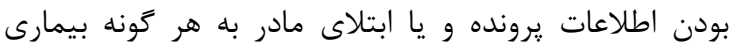

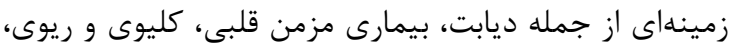

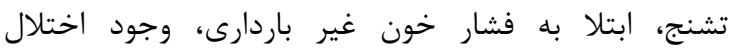

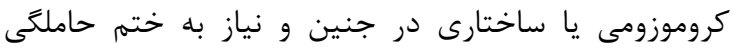

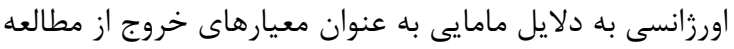

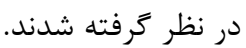
اطلاعات دموكرافيك، بارورى و ييامدهاى مادرى و نوزادى

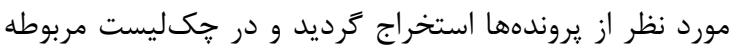

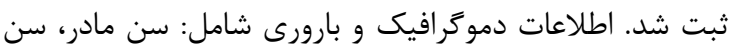

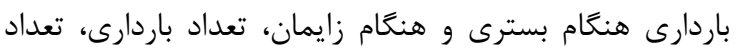

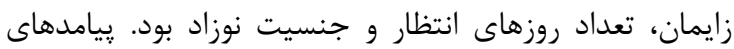

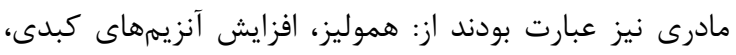

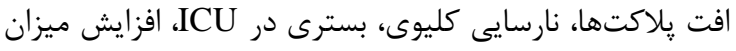

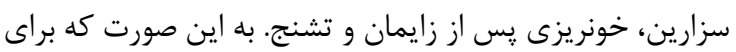

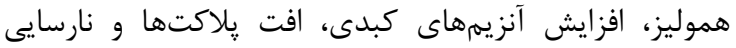

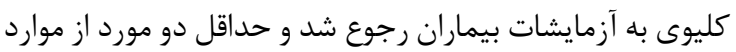

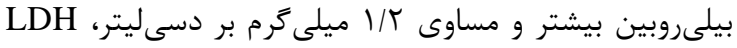

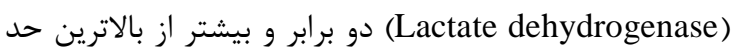

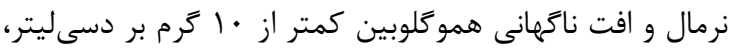

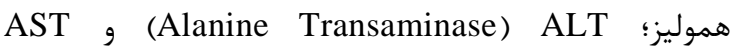
دو برابر و بيشتر از بالاترين حد (Aspartate Transaminase)

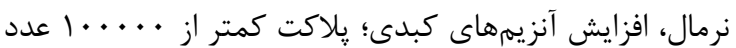

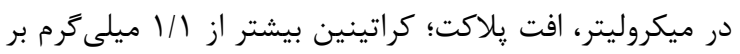

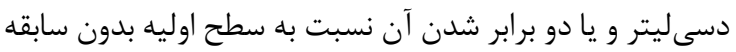

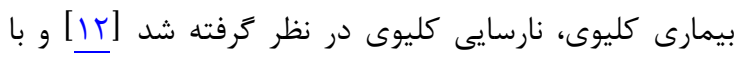

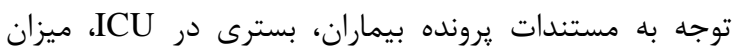

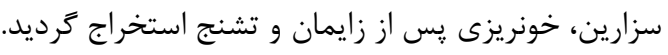
در اين مطالعه بيامدهاى نوزادى شامل: مردمزايى، مركى

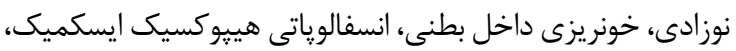

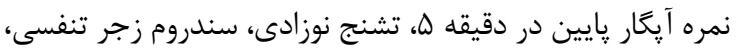

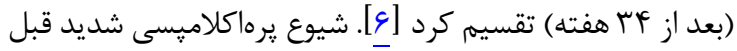

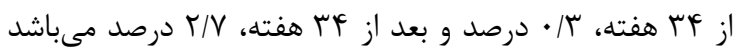

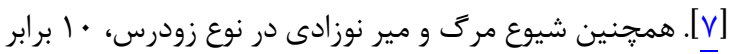

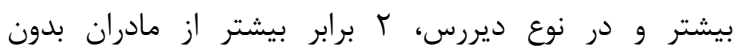
يرهاكلاميسى است [عاع. در ارتباط با عوارض مادرى يرهاكلاميسى مىتوان به به نكروز

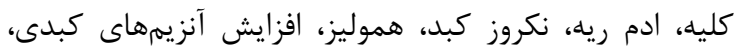
ترومبوسيتوينى و حوادث عروق مغزى اشاره كرد [1]]. در زمينه

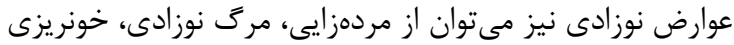

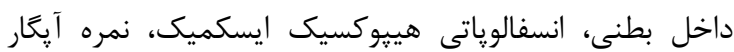

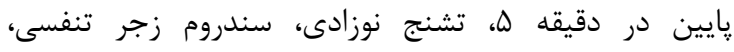

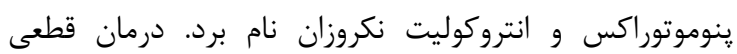

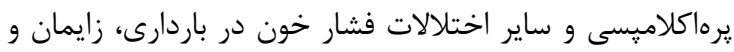

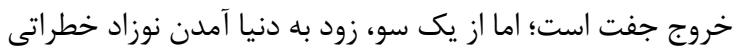

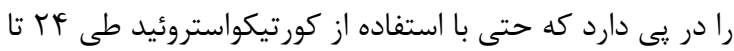

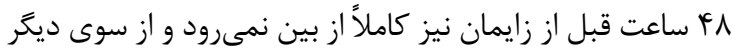

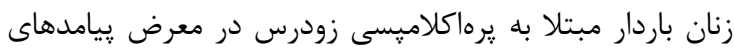

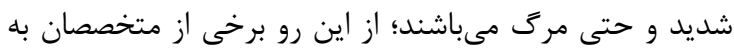

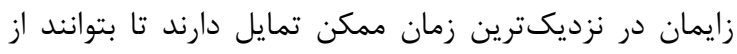

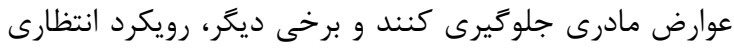

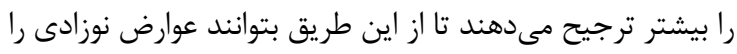

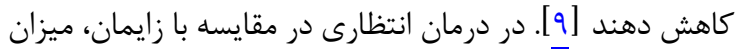

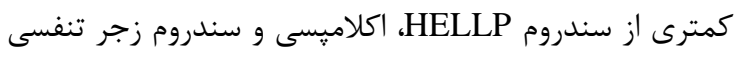

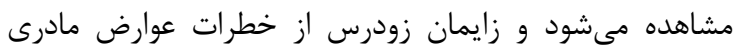

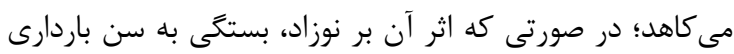

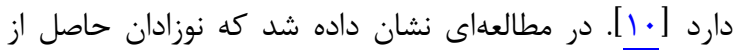

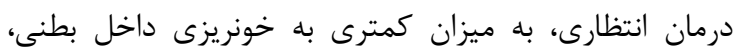

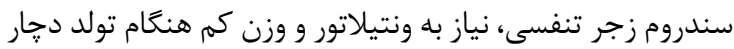

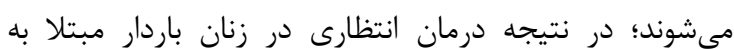

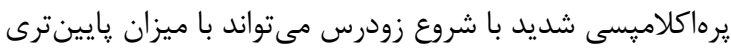

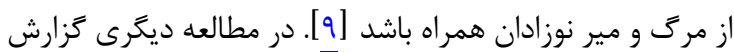

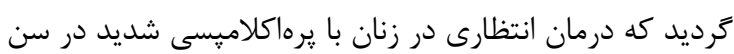

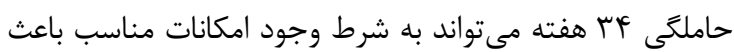

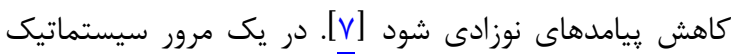

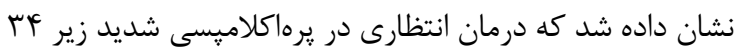

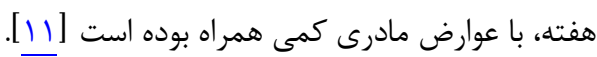

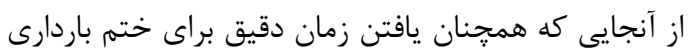

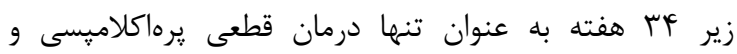

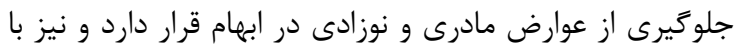

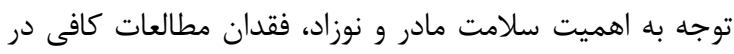

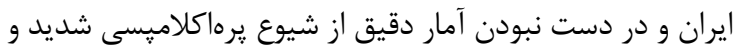

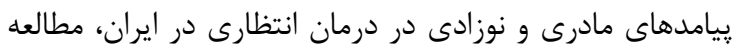

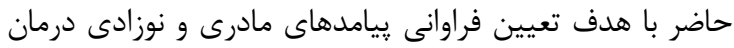

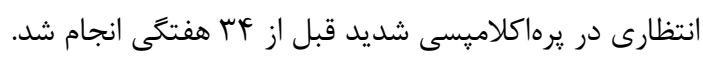


باردارى و تعداد زايمان استفاده كرديد. سطح معنادارى كمتر از

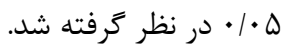

\section{يافته ها}

نتايج نشان مئدهند كه ميانكين سنى بيماران

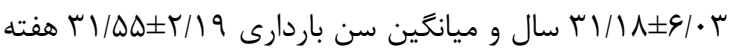

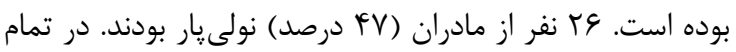

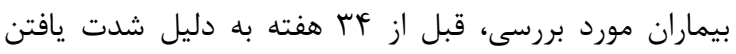

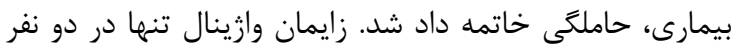

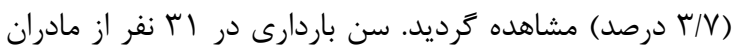

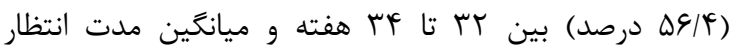

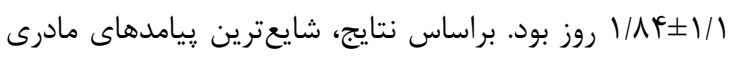

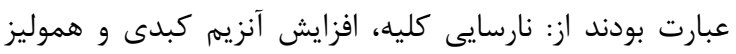

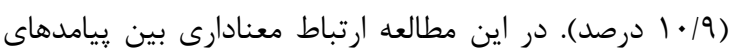

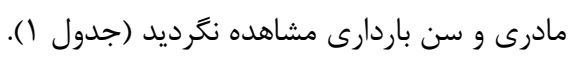

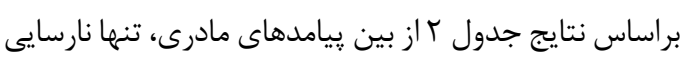

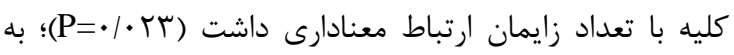
طورى كه تمام مادران مبتلا به نارسايى كليه در بين نولئي داريارها

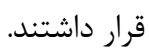

وزن كم نوزاد، ينوموتوراكس و انتروكوليت نكروزان بررسى شدند و

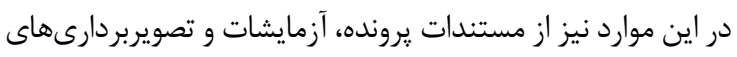

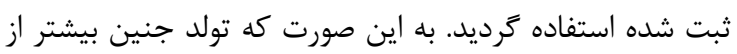

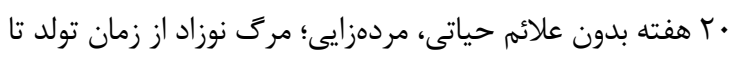

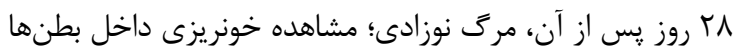

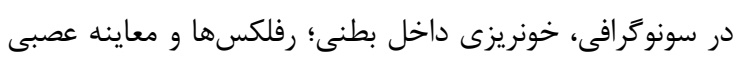

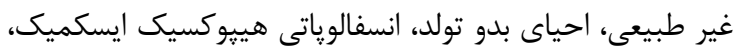

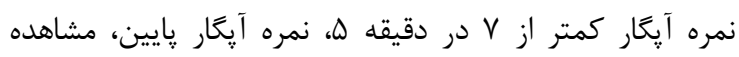

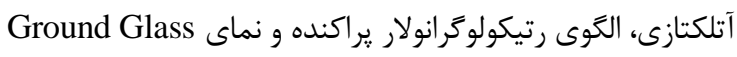

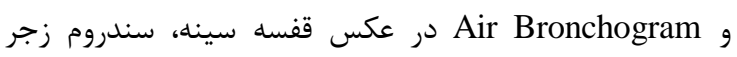

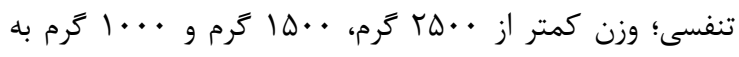

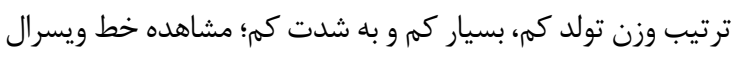

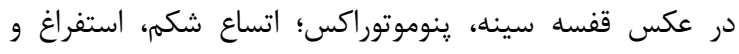

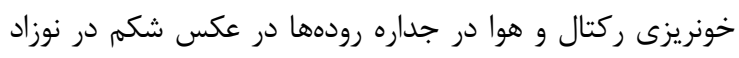

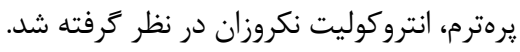

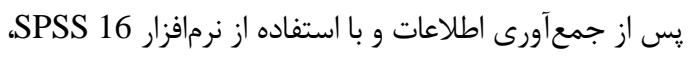

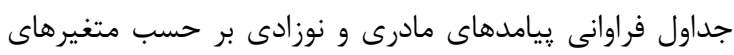

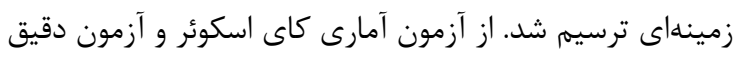

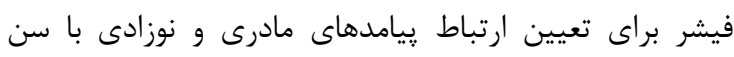

جدول ا: توزيع فراوانى يِيامدهاى مادران مبتلا به برهاكلاميسى بر حسب سن باردارى اهر

\begin{tabular}{|c|c|c|c|c|c|}
\hline سطح معنادارى & 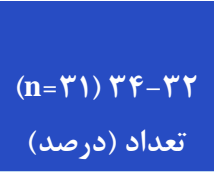 & 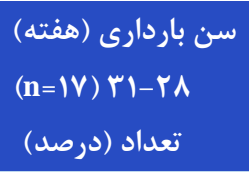 & 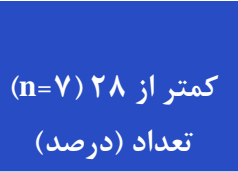 & $\begin{array}{c}\text { تعداد (درصد) } \\
(\mathbf{n}=\Delta \Delta)\end{array}$ & 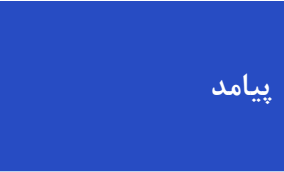 \\
\hline • & $(9 / \mathrm{V}) \mathrm{r}$ & · & . & $(\Delta / \Delta) \Gamma$ & تشنج \\
\hline $.19 V F$ & $(\Gamma / T) 1$ & . & . & $(1 / \wedge) 1$ & خونريزى يس از زايمان \\
\hline .1941 & $(9 / V) r$ & $(1) / \Lambda) r$ & $(\mid F / \mu) \mid$ & $(1 \cdot / 9)^{9}$ & نارسايى كليه \\
\hline$\cdot 1 \cdot \Delta 9$ & $\cdot$ & $(\mid V / \varepsilon) r$ & $(\mid F / \mu) \mid$ & $(V / T) Y$ & افت يلاكت \\
\hline$\cdot 19 \cdot V$ & $(1 T / 9) F$ & $(1) / \wedge) r$ & $\cdot$ & $(1 \cdot / 9)^{9}$ & افزايش آنزيم كبد \\
\hline . $/ 941$ & $(9 / V) r$ & $(1) / \Lambda) r$ & $(\mid F / \mu) \mid$ & $(1 \cdot / 9)^{9}$ & هموليز \\
\hline$\cdot / \mathrm{VV}$ & $(r / T) 1$ & $(\$ / 9) 1$ & . & $(\Gamma / 9) r$ & بسترى در ICU \\
\hline
\end{tabular}

جدول r: توزيع فراوانى بِيامدهاى مادران مبتلا به يرهاكلامٍِى بر حسب تعداد زايمان

\begin{tabular}{|c|c|c|c|c|c|}
\hline \multicolumn{5}{|c|}{ تعداد زايمان } & \multirow[b]{2}{*}{ متغير } \\
\hline سطح معنادارى & 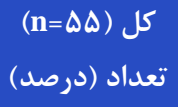 & $\begin{array}{c}(n=\mid l) \geq Y \\
\text { تعداد (درصد) }\end{array}$ & 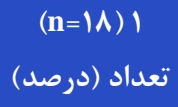 & $\begin{array}{c}(n=r \&) \\
\text { تعداد (درصد) }\end{array}$ & \\
\hline . IGFT & $(\Delta / \Delta) \Gamma$ & · & $(\Delta / 4) 1$ & $(V / V) r$ & تشنج \\
\hline$\cdot \mid \Delta S V$ & $(1 / \wedge) 1$ & · & · & $(\Gamma / \Lambda) 1$ & خونريزى يس از زايمان \\
\hline 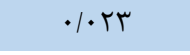 & $(1 \cdot 19)^{9}$ & · & · & $(T+/ 1)^{9}$ & نارسايى كليه \\
\hline$\cdot / r q$. & $(I V / T) F$ & $(\mid \Lambda / T) Y$ & $(\Delta / 9) 1$ & $(\Gamma / \Lambda) 1$ & افت هلاكت \\
\hline .1949 & $(1 \cdot / 9)^{9}$ & $(9 / 1) 1$ & $(19 / V) r$ & $(V / V) r$ & افزايش آنزيم كبد \\
\hline$\cdot / r q$. & $(1 \cdot / 9)^{8}$ & · & $(11 / 1) r$ & $(1 \Delta / F) F$ & هموليز \\
\hline.$/ 111$ & $(r / \varphi) r$ & · & $(11 / 1) r$ & · & بسترى در ICU \\
\hline
\end{tabular}


جدول بّ: توزيع فراوانى پيامدهاى نوزادى در مادران مبتلا به برهاكلامٍسى بر حسب سن باردارى

\begin{tabular}{|c|c|c|c|c|c|c|}
\hline معنادارى سطح & 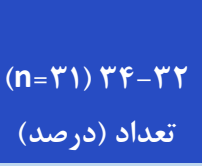 & شن باردارى (هفته) & كمتر از ^ تعداد (درصد) & $\begin{array}{c}\text { تعداد (درصد) } \\
(n=\Delta \Delta)\end{array}$ & & ييامد \\
\hline$\cdot 1 \cdot$ & · & - & $(F Y / Q) r$ & $(\varepsilon / \mathcal{F}) r$ & & مرى \\
\hline $.19 Y \wedge$ & $(\mathcal{F} / T) 1$ & $(\varepsilon / \Gamma) 1$ & $(\mid F / T) \mid$ & $(\varepsilon / \mathcal{Y}) r$ & & تشنج \\
\hline$\cdot 1 \cdot \cdot 9$ & $(T \Delta)^{\varphi}$ & $(\Delta r / \varphi) q$ & $(\Lambda \Delta / \vee)^{\&}$ & $(F F / V) Y I$ & \multicolumn{2}{|c|}{ سندروم زجر تنفسى } \\
\hline$\cdot / \vee q 1$ & $(\boldsymbol{F} / T) 1$ & $(\varepsilon / \Gamma) 1$ & $\cdot$ & $(r / r) r$ & \multicolumn{2}{|c|}{ انتروكوليت نكروزان } \\
\hline$\cdot / \cdot \varphi \Delta$ & $\begin{array}{c}(Y Y / Q) V \\
(Y F / T) Y T \\
(Y / T) 1 \\
\cdot \\
(Y Y / Y) T F\end{array}$ & $\begin{array}{c}\cdot \\
(F / T) \vee \\
(r \Delta / r) q \\
(r T / \Delta) F \\
(1 \cdot \cdot) \mid V\end{array}$ & $\begin{array}{c}\cdot \\
(F T / q) r \\
(\mid F / T) \mid \\
(F T / q) r \\
(1 \cdots) V\end{array}$ & $\begin{array}{l}(I T / V) V \\
(G \cdot) r r \\
(I T / V) V \\
(I F / \Delta) \wedge\end{array}$ & بـ بايين & وزن \\
\hline$\cdot 1 \cdot \cdot 1$ & $(\varepsilon / \Delta) r$ & $(\Delta / 9))$ & $(\Delta V / I) F$ & · & \multicolumn{2}{|c|}{ آيخار یايين دقيقه ه } \\
\hline$\cdot / \cdot r \Delta$ & $\cdot$ & $(\varphi / \Gamma) 1$ & $(Y \wedge / 9) Y$ & $(I T / V) V$ & \multicolumn{2}{|c|}{ ينوموتوراكس } \\
\hline$\cdot / \vee 91$ & $(\boldsymbol{F} / T) 1$ & $(\varepsilon / \Gamma) 1$ & $\cdot$ & $(\varphi / \mathcal{F}) r$ & \multicolumn{2}{|c|}{ خونريزى داخل بطنى } \\
\hline
\end{tabular}

ينوموتور اكس با سن باردارى ارتباط معنادارى داشتند؛ به طورى

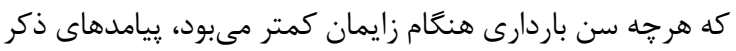

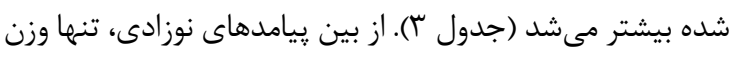

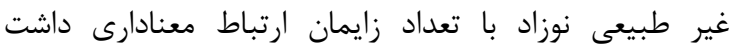

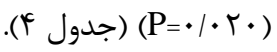

شايعترين ييامدهاى نوزادى نيز عبارت بودند از: سندروم زجر

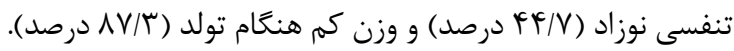

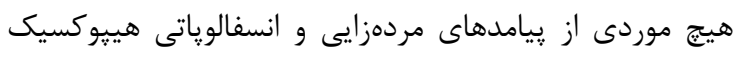

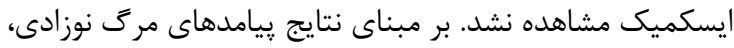

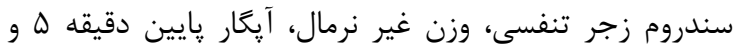

جدول f: توزيع فراوانى پِيامدهاى نوزادى در مادران مبتلا به يرهاكلاميسى بر حسب تعداد زايمان

\begin{tabular}{|c|c|c|c|c|c|}
\hline سطع سعادارى & $\begin{array}{c}\text { كل تعداد (درصد) } \\
(n=\Delta \text { (n) }\end{array}$ & تعداد زايمان & $\begin{array}{c}(n=\mid \Lambda) \mid \\
\text { تعداد (درصد) }\end{array}$ & 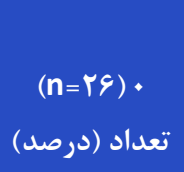 & بيامد \\
\hline $.1 \cdot 9$ & $\left(\varepsilon / F^{\mathrm{F}}\right) r$ & $(Y \cdot) Y$ & $(V / V) 1$ & · & مرك \\
\hline.$/ 1 r r$ & $(\varepsilon / \mathcal{Y}) r$ & $(r \cdot) r$ & $\cdot$ & $(\mathbb{E} / T) 1$ & تشنج \\
\hline . /RNT & $(F F / Y) Y I$ & $(\varphi \cdot)^{\varphi}$ & $(\& \& / T)^{q}$ & $(r V / \Delta) 9$ & سندروم زجر تنفسى \\
\hline$\cdot 10 \cdots$ & $(F / T) r$ & $(1 \cdot) 1$ & $\cdot$ & $(F / T) 1$ & انتروكوليت نكروزان \\
\hline.$/ \cdot r$. & $\begin{array}{l}(I Y / V) \vee \\
(G \cdot) r T \\
(I Y / \Delta) \wedge \\
(I Y / V) \vee\end{array}$ & $\begin{array}{c}\cdot \\
(\varepsilon r / \varepsilon) V \\
(r / / \mathcal{F}) F\end{array}$ & $\begin{array}{l}(11 / 1) r \\
(V T / T) \mid r \\
(Q / 9) 1 \\
(11 / 1) r\end{array}$ & $\begin{array}{l}(19 / 4) \Delta \\
(\Delta \cdot) \mid r \\
(Y \& / 9) \vee \\
((T / \Lambda) \backslash\end{array}$ & 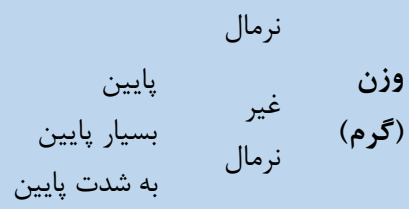 \\
\hline$\cdot / \cdot \Delta \cdot$ & $(I T / V) V$ & $(r \varepsilon / F) F$ & $(\Delta / 8) 1$ & $(V / V) T$ & آيعار پايين دقيقه ه \\
\hline$\cdot / T \& V$ & $\left(\varepsilon / \varphi^{c}\right) r$ & · & $(\mid \Delta / F) r$ & $(F / T) 1$ & ينوموتوراكس \\
\hline . MTY & $(\boldsymbol{r} / \Gamma) r$ & $(1 \cdot) 1$ & $(V / V) 1$ & $\cdot$ & خونريزى داخل بطنى \\
\hline
\end{tabular}

تنفسى نوزاد و وزن كم هنگام تولد بود. بر مبناى نتايج، ييامدهاى

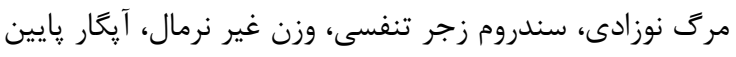

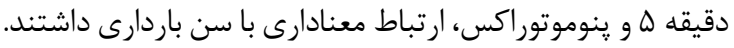

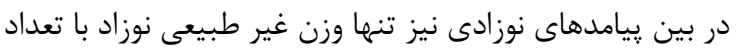

نتايج مطالعه حاضر نشان دادند كه شايعترين ييامدهاى

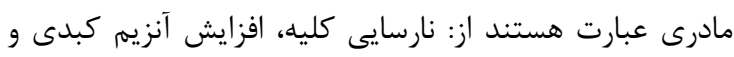

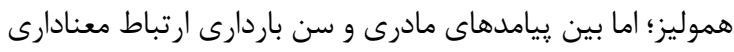

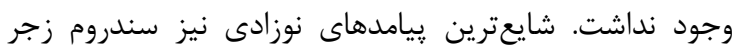




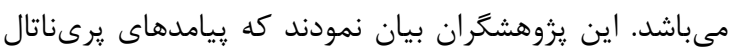

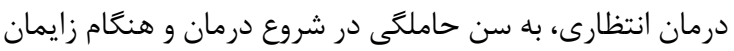

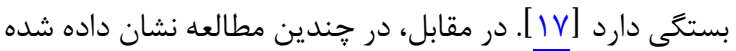
است كه در سن باردارى كمتر از ب M هفته، درمان انتظارى به ميزان

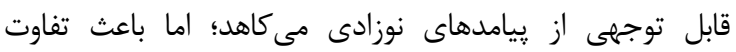

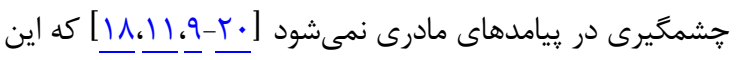

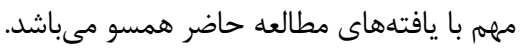

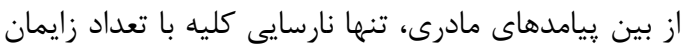

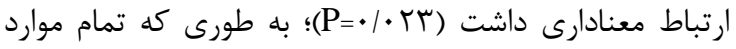

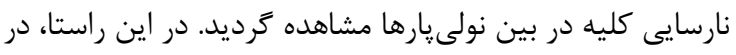

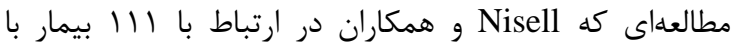

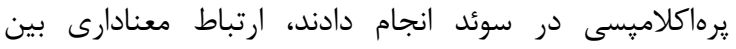

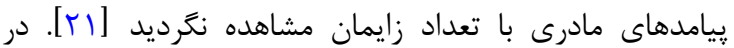

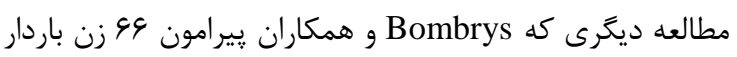

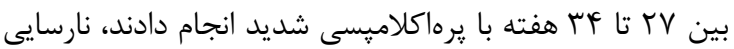

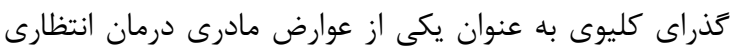

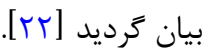
در اين مطالعه به غير از وزن غير طبيعى نوزاد، ساير

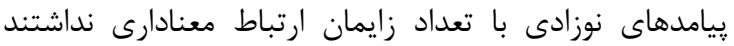

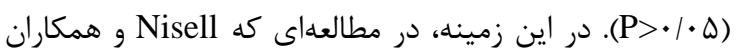

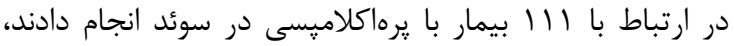

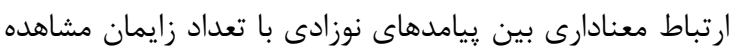

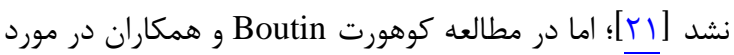

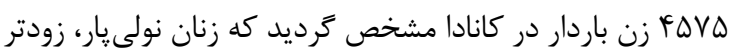

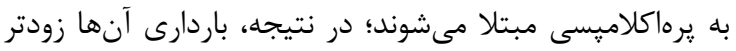

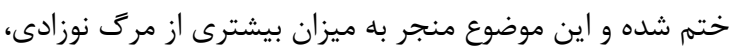

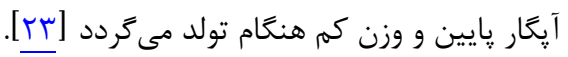

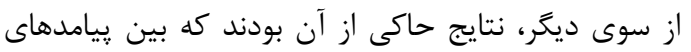

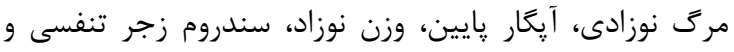

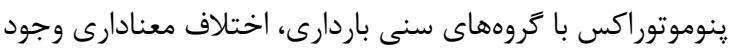

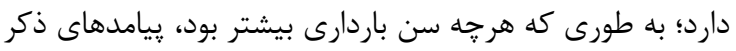

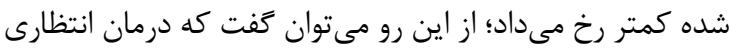

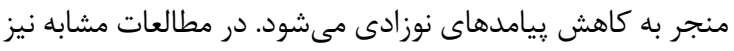

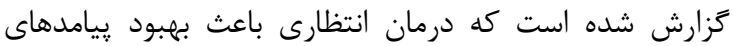

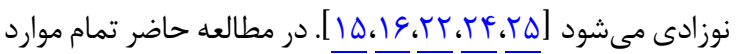

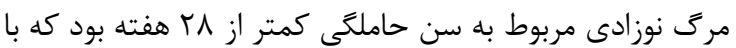

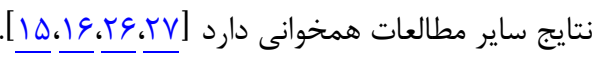

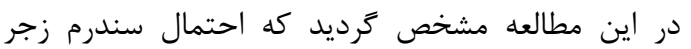

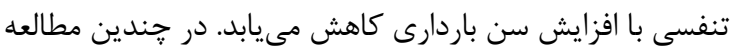

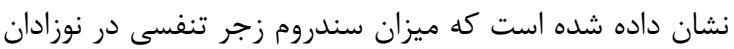

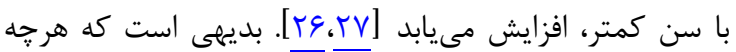

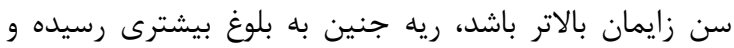

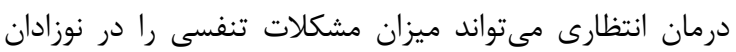

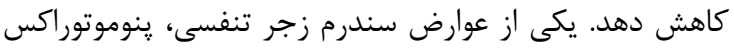

زايمان ارتباط معنادارى داشت.

در مطالعه حاضر اكثر مادران در گروه سنى اس تا هـ سال

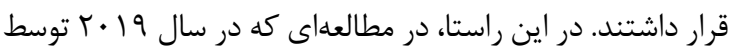
Kartikadewi

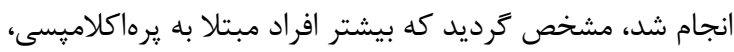

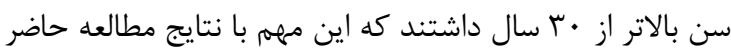

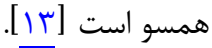
در مطالعه حاضر مشخص گرديد كه س FV/T درصد از مادران،

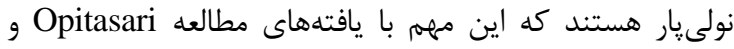

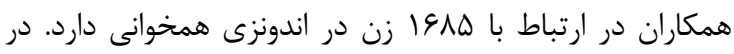

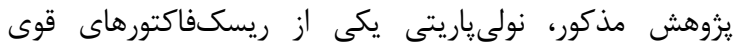

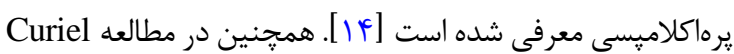

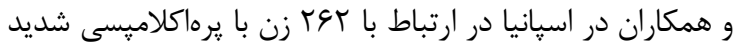

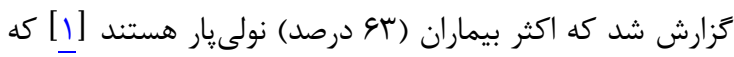

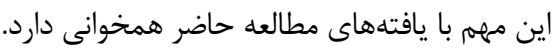

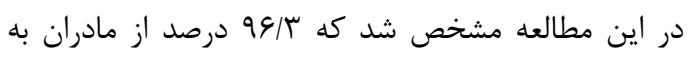
روش سزارين زايمان كردهاند. در يك مطالعه مولتى سنتر در

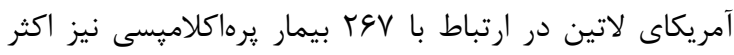

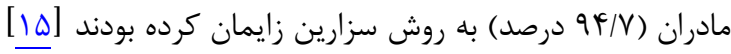

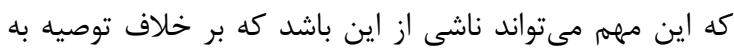

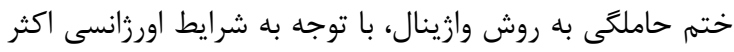

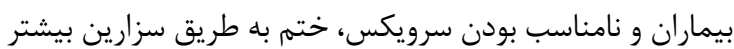

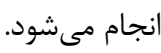

در اين مطالعه هيج كدام از زيّامدهاى مادرى با تعداد

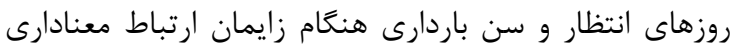

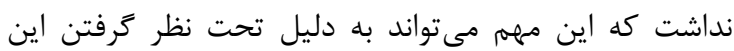

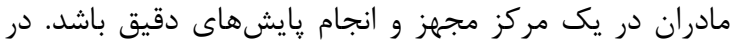

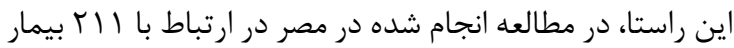
با برهاكلاميسى شديد مشخص شد كه ميانگين و انحراف معيار

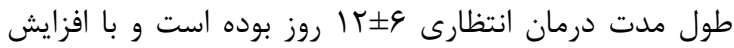

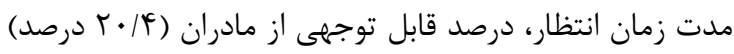

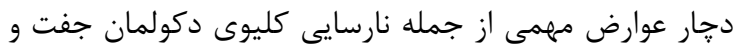
HELLP

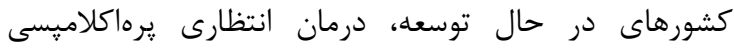

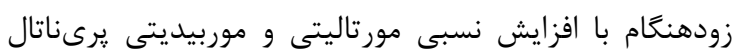

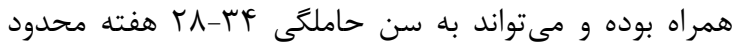

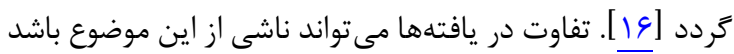

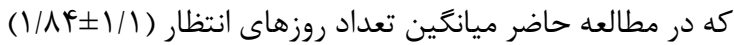

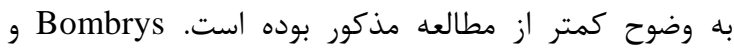

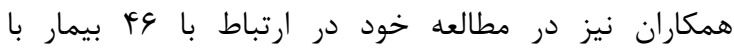

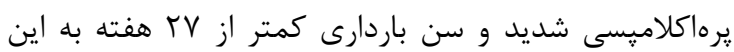

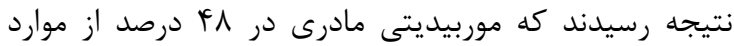

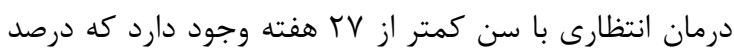

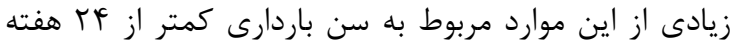




$$
\text { بدتر شدن وضعيت مادر و جنين ضرورت مىيابد. }
$$

$$
\text { تشكر و قلر داذى }
$$

اين مقاله بركرفته از پاياننامه دكترى حرفهاى يزشكى دانى

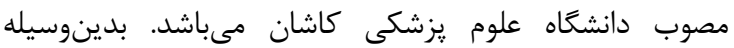
نويسندكان مراتب تقدير و تشكر خود را از حمايتهاى مُنس معاونت يزووهشى دانشكاه اعلام مى نمايند.

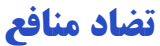
نويسند ندارند.

\section{ملاحظات اخلاقى}

اين مطالعه داراى تأييديه از كميته اخلاق دانشعاه علوم

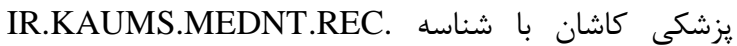
1399.134 مىباشد.

\section{سمهم نو سيندكان}

نويسنده اول (يزوهشگر اصلى): طراحى يروزه، مشاركت در

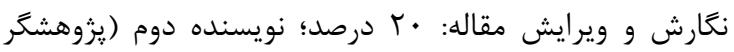
اصلى): مشاور علمى طرح، مشاركت در نكارش و ويرايش مقاله:

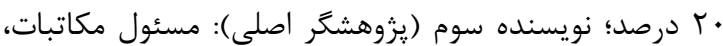

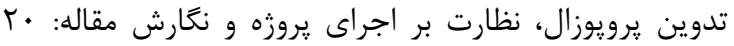

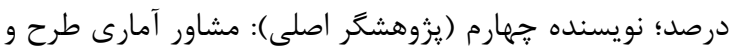

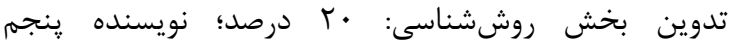

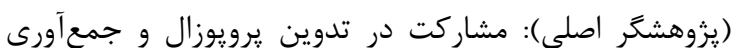

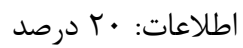

\section{حمايت مالى}

طرح حاضر از سوى معاونت يزوهشى دانشخاه علوم يزشكى

$$
\text { كاشان تأمين مالى شده است. }
$$

\section{REFERENCES}

1. Curiel-Balsera E, Prieto-Palomino M, Munoz-Bono J, de Elvira MR, Galeas J, García GQ. Analysis of maternal morbidity and mortality among patients admitted to Obstetric Intensive Care with severe preeclampsia, eclampsia or HELLP syndrome. Med Intensiva. 2011;35(8):478-83. PMID: 21703718 DOI: 10.1016/j.medin.2011.05.011

2. Jeyabalan A. Epidemiology of preeclampsia: impact of obesity. Nutr Rev. 2013;71(Suppl 1):S18-25. PMID: 24147919 DOI: $10.1111 /$ nure. 12055

3. Rylander R. Pre-eclampsia during pregnancy and cardiovascular disease later in life: the case for a risk group. Arch Gynecol Obstet. 2015;292(3):519-21. PMID: 25721023 DOI: $10.1007 / \mathrm{s} 00404-015-3676-3$

4. Kharaghani R, Cheraghi Z, Esfahani BO, Mohammadian Z, Nooreldinc RS. Prevalence of preeclampsia and eclampsia in Iran. Arch Iranian Med. 2016;19(1)64-71. PMID: 26702751

5. Khan KS, Wojdyla D, Say L, Gülmezoglu AM, Van Look PF. WHO analysis of causes of maternal death: a systematic review. Lancet. 2006;367(9516):1066-74. PMID: 16581405
است كه به تبعيت از سندرم زجر تنفسى با كاهش سن زايمان،

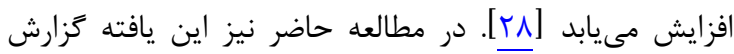

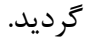

در مطالعهاى كه در سال ז + . م در ارتباط با وسז زن باردار بين fr تا س هفته با ڤيرهاكلامٍسى شديد در فرانسه انجام شد، مشخص كرديد كه با كاهش سن زايمان، ميزان آيعار گِايين و

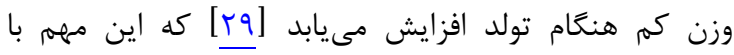
يافتههاى مطالعه حاضر تطابق دارد. همجنين در مطالعه Bombrys

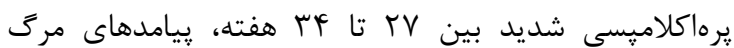
نوزادى، وزن كم هنگام تولد و سندروم زجر تنفسى در نوزادان كمتر از rr هفته به وضوح بيشتر از نوزادان بالاى بr هفته بود

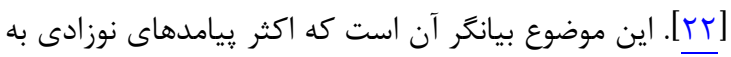
طور معنادارى با سن زايمان ارتباط دارد و درمان انتظارى باعث كاهش اين ييامدها مىشود. در انتها بايد خاطرنشان ساخت كه يكى از محدوديتهاى مطالعه حاضر اين بود كه به صورت كذشتهنگر انجام شد و در برخى از موارد، ثبت ناقص اطلاعات در يروندهها باعث از دست رفتن نمونهها و يا عدم دسترسى به دادههاى مورد نياز مى گرديد؛ از اين رو ريشنههاد مىشود مطالعات بعدى در راستاى مقايسه درمان انتظارى با درمان مداخلهاى با حجم نمونه بالاتر، مدت انتظار بيشتر و به صورت آيندهنگر طراحى و اجرا گردند.

\section{نتيجه كيرى}

درصد زيادى از ييامدهاى نوزادى در سنين يايينتر زايمان رخ مى دهند و درمان انتظارى در پرهاكلاميسى با شروع زودرس مىتواند به ميزان زيادى براى نوزاد مفيد باشد؛ اما عوارض مادرى را به شرط در دسترس بودن امكانات درمانى و يايشهاى دقيق و منظم افزايش نمى دهد. در هر حال، درمان انتظارى در هر بيمار با توجه به شرايط همان شخص متفاوت مىباشد و در عمل، رويكرد ڤزشكان مختلف در انتخاب درمان انتظارى به عنوان مديريت يرهاكلاميسى شديد متفاوت بوده و انجام زايمان در موارد

DOI: $10.1016 / \mathrm{S} 0140-6736(06) 68397-9$

6. Lisonkova S, Joseph K. Incidence of preeclampsia: risk factors and outcomes associated with early-versus late-onset disease. Am J Obstet Gynecol. 2013;209(6):544.e1-12. PMID: 23973398 DOI: 10.1016/j.ajog.2013.08.019

7. Publications Committee, Society for Maternal-Fetal Medicine, Sibai BM. Evaluation and management of severe preeclampsia before 34 weeks' gestation. Am J Obstet Gynecol. 2011;205(3):191-8. PMID: 22071049 DOI: 10.1016/j.ajog.2011.07.017

8. Alvarez RN, Marin R. Severe maternal complications associated with pre-eclampsia: an almost forgotten pathology? Nefrologia. 2001;21(6):565-73. PMID: 11881426

9. Churchill D, Duley L, Thornton JG, Moussa M, Ali HS, Walker KF. Interventionist versus expectant care for severe pre-eclampsia between 24 and 34 weeks' gestation. Cochrane Database Syst Rev. 2018;10(10):CD003106. PMID: 30289565 DOI: 10.1002/14651858.CD003106.pub3

10. Bernardes T, Zwertbroek E, Broekhuijsen K, Koopmans C, 
Boers K, Owens M, et al. Delivery or expectant management for prevention of adverse maternal and neonatal outcomes in hypertensive disorders of pregnancy: an individual participant data meta-analysis. Ultrasound Obstet Gynecol. 2019; 53(4):443-53. PMID: 30697855 DOI: 10.1002/uog.20224

11. Magee L, Yong P, Espinosa V, Cote A, Chen I, Von Dadelszen P. Expectant management of severe preeclampsia remote from term: a structured systematic review. Hypertens Pregnancy. 2009;28(3):312-47. PMID: 19277923 DOI: 10.1080/10641950802601252

12. Cunningham F, Leveno K, Bloom S, Dashe J, Spong C, Hauth J, et al. Williams obstetrics. $25^{\text {th }}$ ed. New York: McGraw-Hill Education; 2018.

13. Kartikadewi R, Theresia EM, Meilani N. Age, parity and birth spacing to the incidence of preeclampsia. Int J Public Health Sci. 2019;8(1):45-50. DOI: 10.11591/ijphs.v8i1.16646

14. Opitasari C, Andayasari L. Parity, Education level and risk for (pre-) eclampsia in selected hospitals in Jakarta. Health Sci J Indonesia. 2014;5(1):35-9.

15. Vigil-De Gracia P, Tejada OR, Miñaca AC, Tellez G, Chon VY, Herrarte E, et al. Expectant management of severe preeclampsia remote from term: the MEXPRE Latin Study, a randomized, multicenter clinical trial. Am J Obstet Gynecol. 2013;209(5):425.e1-8. PMID: 23954534 DOI: 10.1016/j.ajog.2013.08.016

16. Abdel-Hady ES, Fawzy M, El-Negeri M, Nezar M, Ragab A, Helal AS. Is expectant management of early-onset severe preeclampsia worthwhile in low-resource settings? Arch Gynecol Obstet. 2010;282(1):23-7. PMID: 19693521 DOI: 10.1007/s00404-009-1209-7

17. Bombrys AE, Barton JR, Nowacki EA, Habli M, Pinder L, How $\mathrm{H}$, et al. Expectant management of severe preeclampsia at less than 27 weeks' gestation: maternal and perinatal outcomes according to gestational age by weeks at onset of expectant management. Am J Obstet Gynecol. 2008;199(3):247.e1-6. PMID: 18771971 DOI: 10.1016/j.ajog.2008.06.086

18. Guida JPS, Surita FG, Parpinelli MA, Costa ML. Preterm preeclampsia and timing of delivery: a systematic literature review. Rev Bras Ginecol Obstet. 2017;39(11):622-31. PMID: 28701023 DOI: $10.1055 / \mathrm{s}-0037-1604103$

19. Sibai BM, Barton JR. Expectant management of severe preeclampsia remote from term: patient selection, treatment, and delivery indications. Am J Obstet Gynecol. 2007;196(6): 514.e1-9. PMID: 17547875 DOI: 10.1016/j.ajog.2007.02.021
20. Wang Y, Hao M, Sampson S, Xia J. Elective delivery versus expectant management for pre-eclampsia: a meta-analysis of RCTs. Arch Gynecol Obstet. 2017;295(3):607-22. PMID: 28150165 DOI: $10.1007 / \mathrm{s} 00404-016-4281-9$

21. Nisell H, Palm K, Wolff K. Prediction of maternal and fetal complications in preeclampsia. Acta Obstet Gynecol Scand. 2000;79(1):19-23. PMID: 10646811

22. Bombrys AE, Barton JR, Habli M, Sibai BM. Expectant management of severe preeclampsia at $27(0 / 7)$ to $33(6 / 7)$ weeks' gestation: maternal and perinatal outcomes according to gestational age by weeks at onset of expectant management. Am J Perinatol. 2009;26(6):441-6. PMID: 19288398 DOI: $10.1055 / \mathrm{s}-0029-1214243$

23. Boutin A, Guerby P, Gasse C, Tapp S, Bujold E. Pregnancy outcomes in nulliparous women with positive first-trimester preterm preeclampsia screening test: the Great Obstetrical Syndromes cohort study. Am J Obstet Gynecol. 2021;224(2): 204.e1-7. PMID: 32777265 DOI: 10.1016/j.ajog.2020.08.008

24. Ndoni E, Hoxhallari R, Bimbashi A. Evaluation of maternal complications in severe preeclampsia in a university hospital in Tirana. Open Access Macedonian J Med Sci. 2016;4(1): 102-6. PMID: 27275340 DOI: 10.3889/oamjms.2016.025

25. Sibai BM, Mercer BM, Schiff E, Friedman SA. Aggressive versus expectant management of severe preeclampsia at 28 to 32 weeks' gestation: a randomized controlled trial. Am J Obstet Gynecol. 1994;171(3):818-22. PMID: 8092235 DOI: 10.1016/0002-9378(94)90104-X

26. Swamy M, Patil K, Nageshu S. Maternal and perinatal outcome during expectant management of severe preeclampsia between 24 and 34 weeks of gestation. J Obstet Gynecol India. 2012;62(4):413-8. PMID: 23904701 DOI: 10.1007/s13224-012-0293-y

27. Vijayan N, Keepanasseril A, Plakkal N, Udupa V, Raghavan S. Maternal and perinatal outcomes in women undergoing expectant management of early-onset pre-eclampsia: A retrospective cohort study. South Afr J Obstet Gynaecol. 2018;24(3):83-6. DOI: 10.7196/sajog. 1378

28. Marcdante K, Kliegman RM. Nelson essentials of pediatrics. $8^{\text {th }}$ ed. New York: Elsevier Health Sciences; 2019. P. 242

29. Haddad B, Deis S, Goffinet F, Paniel BJ, Cabrol D, Sibaï BM. Maternal and perinatal outcomes during expectant management of 239 severe preeclamptic women between 24 and 33 weeks' gestation. Am J Obstet Gynecol. 2004;190(6):1590-5. PMID: 15284743 DOI: $10.1016 /$ j.ajog.2004.03.050 